\title{
Coix lacryma-jobi var. ma-yuen Stapf sprout extract induces cell cycle arrest and apoptosis in human cervical carcinoma cells
}

Eun Suk Son ${ }^{1 \dagger}$, Se-Hee Kim² ${ }^{2 \dagger}$, Young Ock Kim³ ${ }^{3}$ Young Eun Lee ${ }^{1}$, Sun Young Kyung ${ }^{1}$, Sung Hwan Jeong ${ }^{1}$, Yu Jin $\mathrm{Kim}^{4^{*}}$ and Jeong-Woong Park ${ }^{1^{*}}$ (D)

\begin{abstract}
Background: Cervical cancer is the second-leading cause of cancer-related mortality in females. Coix lacryma-jobi L. var. ma-yuen (Rom.Caill.) Stapf ex Hook. f. is the most widely recognized medicinal herb for its remedial effects against inflammation, endocrine system dysfunctions, warts, chapped skin, rheumatism, and neuralgia and is also a nourishing food.

Methods: To investigate the activity of Coix lacryma-jobi sprout extract (CLSE) on cell proliferation in human cervical cancer HeLa cells, we conducted a Cell Counting Kit-8 (CCK-8) assay. Flow-cytometric analysis and western blot analysis were performed to verify the effect of CLSE on the regulation of the cell cycle and apoptosis in HeLa cells.

Results: We observed that CLSE significantly inhibited cell proliferation. Furthermore, CLSE dose-dependently promoted cell cycle arrest at the sub-G1/ S phase in HeLa cells, as detected by bromodeoxyuridine (BrdU) staining. The cell-cycle-arrest effects of CLSE in HeLa cells were associated with downregulation of cyclin D1 and cyclindependent kinases (CDKs) 2, 4, and 6. Moreover, CLSE induced apoptosis, as determined by flow-cytometric analysis and nuclear DNA fragmentation with Annexin V/propidium iodide (PI) and 4'6'-diamidino-2-phenylindole (DAPI) staining. Induction of apoptosis by CLSE was involved in inhibition of the antiapoptotic protein B-cell lymphoma 2 (BCl-2) and upregulation of the apoptotic proteins p53, cleaved poly (ADP-ribose) polymerase (PARP), cleaved caspase-3, and cleaved caspase-8. Finally, we observed that CLSE inactivated the phosphoinositide 3-kinase (PI3K) and protein kinase B (AKT) pathways.

Conclusions: CLSE causes cell cycle arrest and apoptotic cell death through inactivation of the PI3K/AKT pathway in HeLa cells, suggesting it is a viable therapeutic agent for cervical cancer owing to its anticancer effects.
\end{abstract}

Keywords: Apoptosis, Cell cycle arrest, Cervical cancer, Coix lacryma-jobi sprout extract

\footnotetext{
* Correspondence: gene2001@kumc.or.kr; jwpark@gilhospital.com

'Eun Suk Son and Se-Hee Kim contributed equally to this work.

${ }^{4}$ Division of Pulmonology, Department of Internal Medicine, Korea University

Ansan Hospital, Gyeonggi-do 15355, Republic of Korea

1 Department of Allergy, Pulmonary and Critical Care Medicine, Gachon

University, Gil Medical Center, Incheon 21565, Republic of Korea

Full list of author information is available at the end of the article
}

(c) The Author(s). 2019 Open Access This article is distributed under the terms of the Creative Commons Attribution 4.0 International License (http://creativecommons.org/licenses/by/4.0/), which permits unrestricted use, distribution, and reproduction in any medium, provided you give appropriate credit to the original author(s) and the source, provide a link to the Creative Commons license, and indicate if changes were made. The Creative Commons Public Domain Dedication waiver (http://creativecommons.org/publicdomain/zero/1.0/) applies to the data made available in this article, unless otherwise stated. 


\section{Background}

Cervical cancer is the second-leading cause of cancerrelated mortality in females [1,2]. Athough the pathological process of cervical cancer is still ambiguous, nearly all cases of cervical cancer are caused by human papillomavirus (HPV) infection [3, 4]. HPV can activate the PI3K/AKT/mTOR pathways and disturb the cellular mechanisms for growth control [5, 6]. Although new chemotherapeutic agents for the most common cancer have developed over the past few decades, the number of cancer-related deaths remains high due to metastasis and drug resistance [7]. Therefore, the development of chemopreventive or chemotherapeutic agents against cervical carcinoma is crucial to reduce the incidence, mortality, and prevalence of this disease [8].

The regulation of cell cycle arrest and apoptotic cell death is an important feature of anticancer agents [9, 10]. The cell cycle is responsible for cell duplication, and cell cycle progression is checked at checkpoints in the G1/S, S, and G2/M phases [11, 12]. These cell cycle checkpoints are triggered by DNA damage and misaligned chromosomes at the mitotic spindle [13]. Deregulations of apoptotic cell death and the cell cycle is associated with aberrant cell proliferation and cancer [14]. Therefore, treatment of tumor cells usually results in the breakdown of the cell cycle machinery, leading to the inhibition of cell proliferation and induction of apoptosis [15].

Several natural products have been demonstrated to have antitumor effects with few side effects. Specifically, these products can kill cancer cells by modulating apoptosis $[16,17]$. In recent years, many studies have investigated the potential anticancer properties of natural products that are considered to be non-toxic and thus may have fewer side effects compared with synthetic compounds [18-21].

Coix lacryma-jobi var. ma-yuen (Rom.Caill.) Stapf ex Hook. $f$. is a tropical plant of the family Poaceae and is native to Southeast Asia, ranging from India through Malaysia to China [22]. It is now widely grown in other places. Coix has high protein content compared with rice and serves as a rice alternative. Previous studies demonstrated that Coix shows apoptotic and antiproliferative effects against human breast cancer, lung cancer, hepatocellular carcinoma cells, colon cancer cells, and histolytic lymphoma [23-28]. Coix sprouts are obtained from seeds during sprouting. Sprouting is the practice of germinating seeds to be eaten raw or cooked. Thus, germination can lead to the development of functional foods that have a positive effect in humans and can help maintain health [29].

Over the past few decades, Coix seeds have been studied extensively, and anticancer mechanisms, including cell cycle arrest and apoptosis, have been discovered.
However, the effects of Coix lacryma-jobi sprout extract (CLSE) on anticancer mechanisms remain elusive. In this study, our goal was to evaluate the antitumor activities of CLSE in human cervical carcinoma cells.

\section{Methods}

\section{Cell culture and reagents}

Human cervical cancer HeLa cells were purchased from the Korean Cell Line Bank (Seoul, South Korea). HeLa cells were maintained in RPMI 1640 (Gibco Cell Culture, Carlsbad, CA, USA) with $1 \%$ penicillin (Gibco), $1 \%$ streptomycin (Gibco), and $10 \%$ fetal bovine serum (Gibco) at $37^{\circ} \mathrm{C}$ in a humidified atmosphere of $5 \% \mathrm{CO}_{2}$.

CLSE was extracted at the Herbal Crop Research Institute, Rural Development Administration (Chungbuk, South Korea) [30]. SC79 was purchased from SigmaAldrich (St. Louis, MO, USA).

\section{Cell proliferation assay}

Cell viability was assessed using the cell counting kit (CCK)-8 (Dojindo Molecular Technologies, Inc., Rockville, MD, USA). HeLa cells were plated in a 96-well plate and treated with CLSE $(0,125,250,500$, or $1000 \mu \mathrm{g} / \mathrm{mL})$ for 24-72 h. Then, cells were incubated with CCK- 8 at $37{ }^{\circ} \mathrm{C}$ for $2 \mathrm{~h}$. The absorbance was measured at $550 \mathrm{~nm}$.

\section{Flow-cytometric analysis of the cell cycle}

After cells were treated with CLSE $(0,250,500$, or $1000 \mu \mathrm{g} / \mathrm{mL}$ ) for $72 \mathrm{~h}$, cells were harvested and then washed with phosphate-buffered saline (PBS). Cell cycle progression was induced by following the manufacturer's instructions for the FITC bromodeoxyuridine (BrdU) Flow Kit (BD Bioscience, San Diego, CA, USA). The cell cycle was monitored by DNA content using a FACSCalibur cell analyzer (BD Bioscience) after the cells were stained to evaluate the sub-G1, G0/G1, S, and G2/M phase rates.

\section{Flow-cytometric analysis of cell apoptosis}

After treatment with CLSE for $72 \mathrm{~h}$, HeLa cells were resuspended in $100 \mu \mathrm{L}$ binding buffer and stained with FITC-annexin and propidium iodide (PI) (BD Bioscience). Then, $400 \mu \mathrm{L}$ binding buffer was added, and the cells were analyzed using a FACSCalibur system. All tests were performed three times independently.

\section{4'6'-Diamidino-2-phenylindole (DAPI) staining}

In brief, HeLa cells were seeded in a 4-well cell culture slide and treated with CLSE $(0-1000 \mu \mathrm{g} / \mathrm{mL})$ for $48 \mathrm{~h}$. The cell monolayer was fixed with $4 \%$ paraformaldehyde. After permeabilization with PBS containing 0.1\% Triton $\mathrm{X}-100$, the cells were incubated with $1 \mu \mathrm{g} / \mathrm{mL}$ DAPI. Finally, the fragmented nuclei and condensed chromatin 
were observed under a confocal microscope (Zeiss, Oberkochen, Germany).

\section{Western blot analysis}

After treatment with CLSE for 24-72 h, HeLa cells were lysed with radioimmunoprecipitation assay (RIPA) buffer (50 mM Tris, $150 \mathrm{mM} \mathrm{NaCl}, 2 \mathrm{mM}$ EDTA, and 1\% NP40) for $5 \mathrm{~min}$ at $4{ }^{\circ} \mathrm{C}$. The primary antibodies for cyclin D1 and cyclin-dependent kinase (CDK) 2, CDK4, CDK6, GAPDH, p18 ${ }^{\mathrm{INK} 4 \mathrm{c}}, \mathrm{p} 21^{\text {Waf1/Cip1 }}, \mathrm{p} 27^{\mathrm{Kip} 1}, \mathrm{p} 53$, poly (ADP-ribose) polymerase (PARP), cleaved caspase-3, cleaved capase-8, Bcl-2, Bcl-2 associated X (Bax), PI3K, phospho-PI3K, AKT, and phospho-AKT (Ser 473) were obtained from Cell Signaling Technology (Danvers, MA, USA). Glyceraldehyde 3-phosphate dehydrogenase (GAPDH) was used as the loading control.

\section{Statistical analysis}

The data values were analyzed as the means \pm standard deviation of three independent experiments. One-way ANOVA followed by Tukey's test was done for data comparison among groups. ${ }^{*} p<0.05, * p<0.01$, and $* * * 0.001$ were considered to indicate statistical significance.

\section{Results}

\section{Effects of CLSE on HeLa cell viability}

To examine whether CLSE regulates the viability of HeLa cells, cells were treated with CLSE $(0-1000 \mu \mathrm{g}$ / $\mathrm{mL}$ ) for $24-72 \mathrm{~h}$, and the cell viability was evaluated using the CCK- 8 assay.

As expected, the cell viability in CLSE-treated cells decreased in a time- and dose-dependent manner (Fig. 1). The half-maximal inhibitory concentration $\left(\mathrm{IC}_{50}\right)$ value of CLSE was $1723,720.8$, and $580.2 \mu \mathrm{g} / \mathrm{mL}$ at 24,48 , and $72 \mathrm{~h}$, respectively.

\section{Effects of CLSE on cell cycle distribution in HeLa cells}

To examine whether CLSE inhibits HeLa cell growth via cell cycle regulation, we investigated the cell cycle distribution using flow cytometry. CLSE (0, 250, 500, and $1000 \mu \mathrm{g} / \mathrm{mL}$ ) decreased the percentage of S phase cells from 26.44 to $20.95 \%, 18.22$, and $15.13 \%$, respectively (Fig. 2a and b). No changes in the G2/M phase population were evident after CLSE treatment, and the G0/G1 phase population was decreased (Fig. 2b). Rather, the proportion of cells with sub-G1 phase was elevated (Fig. 2a and b). The proportion of HeLa cells in the sub-G1 phase was increased to $7.0-31.5 \%$ by treatment with CLSE. The increase in the sub-G1 population indicated that CLSE induced HeLa cell death, because the sub-G1 population represents apoptotic cells. These results suggest that both $S$ phase arrest and apoptotic cell death were increased by CLSE treatment.

To further examine the biochemical events regulated by CLSE, we examined the expression levels of cell cycle regulatory proteins. CLSE dose-dependently reduced the protein levels of cyclin D1, CDK2, CDK4, and CDK6. These proteins regulate $\mathrm{G} 1 / \mathrm{S}$ phase progression, and CLSE significantly inhibited their expression in HeLa cells (Fig. 3a). To determine the regulators involved in cell cycle arrest, the cyclin-dependent kinase inhibitors $\mathrm{p} 18^{\mathrm{INK} 4 \mathrm{c}}, \mathrm{p} 21^{\mathrm{Waf1/Cip} 1}$, and $\mathrm{p} 27^{\mathrm{Kip} 1}$, which regulate cell cycle progression, were investigated using western blot analysis. CLSE treatment showed a markedly increased (6.3-fold) p27 ${ }^{\text {Kip1 }}$ protein level, whereas the protein levels of $\mathrm{p} 18^{\mathrm{INK} 4 \mathrm{c}}\left(2.0\right.$-fold) and $\mathrm{p} 21^{\mathrm{Waf1/Cip} 1}$ (10.0-fold)

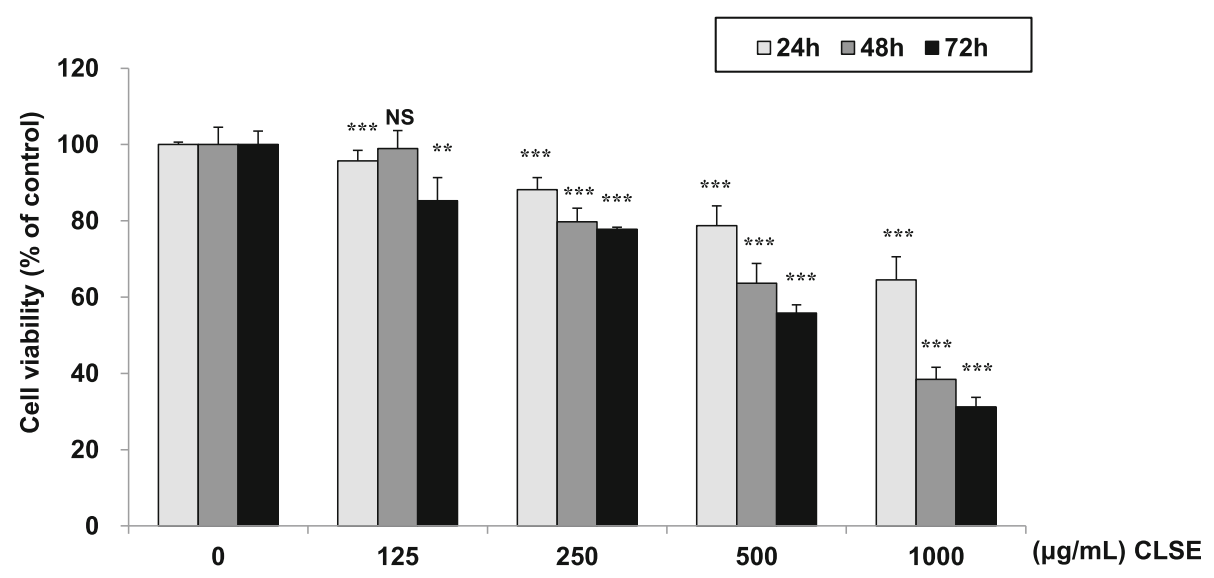

Fig. 1 Cytotoxic effect of Coix lacryma-jobi sprout extract (CLSE) on HeLa cells. Cell viability was assessed by the Cell Counting Kit-8 after treatment with different concentrations of CLSE $(0-1000 \mu \mathrm{g} / \mathrm{mL})$ for $24-72 \mathrm{~h}$. ${ }^{* *} p<0.01$ and ${ }^{* * *} p<0.001$ versus control group. NS, not significant. All data values are expressed as the mean \pm standard deviation $(n=5)$ 

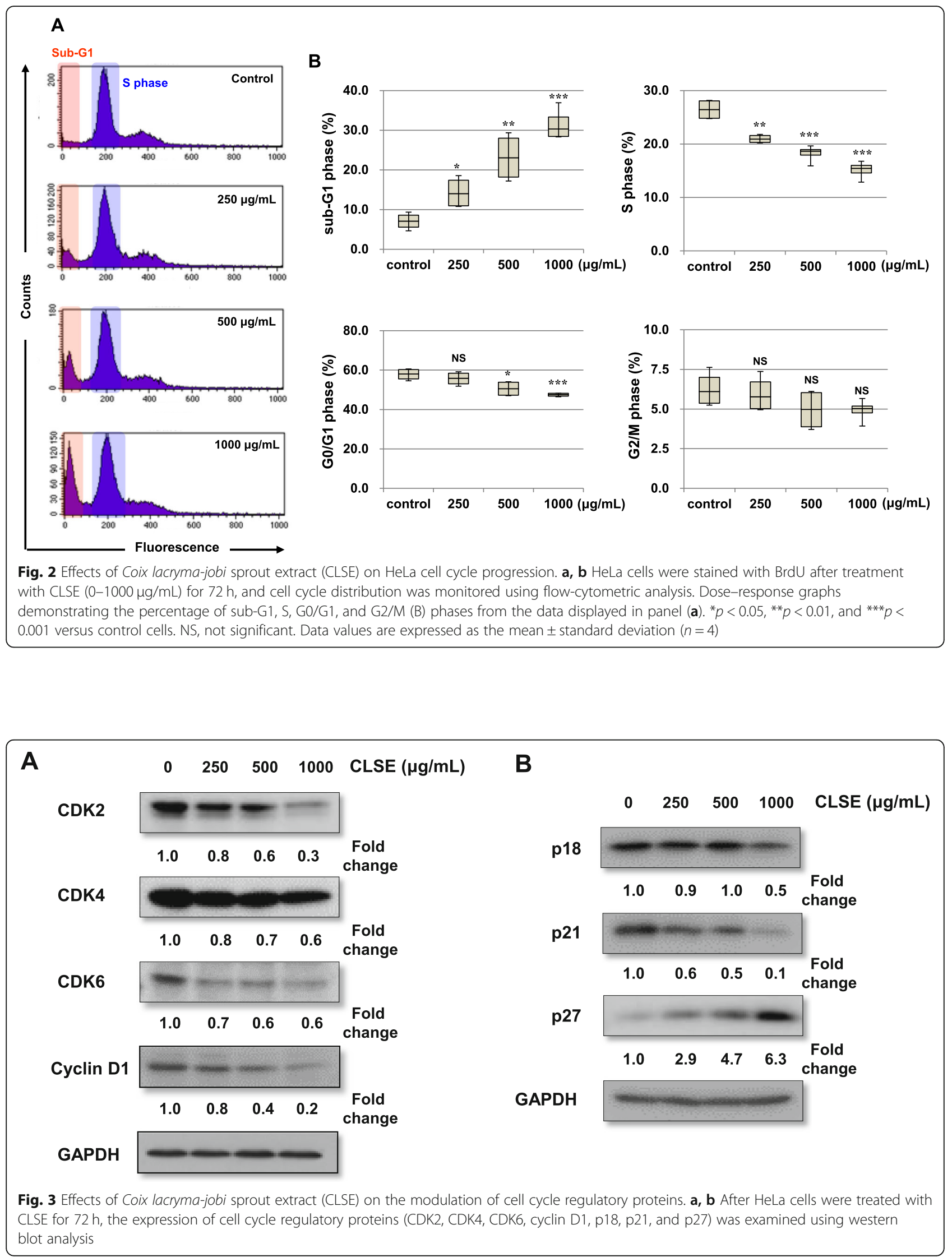
decreased (Fig. 3b). These results suggest that p27 Kip1 caused cell cycle arrest in CLSE-treated HeLa cells.

\section{Effects of CLSE on apoptosis in HeLa cells}

To verify whether CLSE inhibits HeLa cell growth via apoptosis, CLSE-treated HeLa cells were examined using flow cytometry. Annexin $\mathrm{V}$ is a phospholipid-binding protein with high affinity for phosphatidylserine (PS). Apoptotic cells show the redistribution of membrane PS from the inner to the outer leaflet of the plasma membrane. Representative dot plots illustrating apoptotic status are shown in Fig. 4a. Treatment with CLSE (0, 250, 500 , and $1000 \mu \mathrm{g} / \mathrm{mL}$ ) dose-dependently decreased the percentage of viable cells (Annexin $\mathrm{V}^{-} / \mathrm{PI}^{-}$) (Fig. 4b). The proportion of early-apoptotic cells (Annexin $\mathrm{V}^{+}$/ $\mathrm{PI}^{-}$) treated with CLSE increased from 20.68 to $29.41 \%$, 40.01, and 51.77\%, respectively (Fig. 4c). Furthermore, the proportion of late-apoptotic cells (Annexin $\mathrm{V}^{+} / \mathrm{PI}^{+}$) treated with CLSE increased from 8.63 to $15.73 \%, 21.07$ and $28.40 \%$, respectively (Fig. $4 \mathrm{~d}$ ).

Apoptotic cell death manifests in features such as chromatin condensation, cell shrinkage, and nuclear fragmentation. To observe changes within the nucleus during apoptosis of CLSE-treated HeLa cells, we stained CLSE-treated HeLa cells with DAPI. As shown in Fig. 4e, cells treated with CLSE exhibited dose-dependent DNA fragmentation and bright nuclear condensation compared with the control cells.

To investigate whether CLSE-induced apoptosis is mediated by caspases in HeLa cells, we checked the expression levels of the pro-apoptotic proteins PARP, Bax, and cleaved caspase- 3 and the antiapoptotic protein $\mathrm{Bcl}-2$ in CLSE-treated HeLa cells. As shown in Fig. 4f, CLSE decreased Bcl-2 and increased cleaved PARP and cleaved caspase- 3 in HeLa cells. There were no changes in the expression level of Bax. Collectively, these results suggest that increased $\mathrm{Bax} / \mathrm{Bcl}-2$ ratio might be involved in CLSE-induced apoptosis.

\section{Effects of CLSE on the PI3K/AKT pathway}

To identify which signaling pathways are modulated by CLSE, we investigated the expression of PI3K and AKT using western blot analysis. As shown in Fig. 5a, CLSEtreated HeLa cells reduced the phosphorylation of PI3K (5.0-fold) and AKT (2.5-fold) relative to the control group (Fig. 5a). We further confirmed that the activation of AKT was repressed by CLSE using the AKT activator SC79. As expected, treatment with SC79 recovered CLSE's inhibition of the AKT signaling pathway (Fig. 5b). Furthermore, SC79 lowered the protein levels of p27 and cleaved caspase-3 despite the presence of CLSE. Therefore, our results suggest that CLSE induces HeLa cell cycle arrest and apoptosis through inactivation of the PI3K/AKT pathway.

\section{Discussion}

Cervical cancer is the fourth most common cancer in women worldwide and remains a major global health problem [31]. Currently, all applicable anticancer drugs have severe side effects and resistance [32]. Thus, alternative medicines have appeared as new anticancer agents with fewer side effects [33]. Medicinal plants are important sources in the development of anticancer drugs [34].

Recently, a number of studies on the anticancer effects of Coix have been reported. Manosroi et al. demonstrated that the hull of Coix extract has an antiproliferative effect on colon cancer cells [28]. In addition, Coix seed oil injection dulls the pain of cancer patients, and Coix seed oil combined with Norcantharidin reduces hepatocellular carcinoma growth and induces apoptosis $[35,36]$. We also reported that Coix sprout extract suppresses invasion and migration of colon cancer cells and tube formation of human endothelial cells in low-oxygen conditions [30]. Accordingly, recent studies provide a scientific basis for our study of anticancer effects of Coix in human cervical cancer cells.

Additionally, recent studies have focused on identifying the active components of Coix and their mechanisms. Coix contains a large number of lipopolysaccharides, such as stearic acid, palmitic acid, oleic acid, octadecadienoic acid, and linoleic acid. Lu et al. suggest that the polysaccharide fraction of Coix seed is able to inhibit A549 cell proliferation and induce apoptosis [37]. Neutral lipids isolated from Coix inhibit the proliferation of pancreatic cancer cells [38]. Five compounds (coixlactam, methyl dioxindole-3-acetate, and coixspirolactam A, B, and C) isolated from Coix bran inhibit the proliferation of colon and lung cancer cells [26]. Other edible sprouts contain many bioactive phytochemicals, such as isothiocyanates, phenolic acids, flavonoids, and polyphenols, which can perform anticancer functions [39]. We believe that Coix sprout extract will be found to contain similar ingredients as the mature Coix and other generally edible sprouts. For this reason, we will endeavor in our future studies to isolate the active components of Coix sprout extract, which may include coixlactam, neutral lipids, and phytochemicals, and find their possible roles in the anticancer functions of CLSE.

Even though recent studies have demonstrated that Coix has antitumor activities in many cancer cells, studies on the mechanisms of Coix are relatively scarce. In our previous study, a sprout extract of Coix inhibited the metastasis of colon cancer cells; CLSE showed inhibitory effects on invasion, migration, adhesion, and wound healing of colon cancer cells [30]. However, the signaling pathways regulated by CLSE in cervical cancer have not been reported. Thus, in this study, we examined whether CLSE exhibited anticancer activity through cell cycle arrest and apoptotic cell death in cervical cancer cells. 


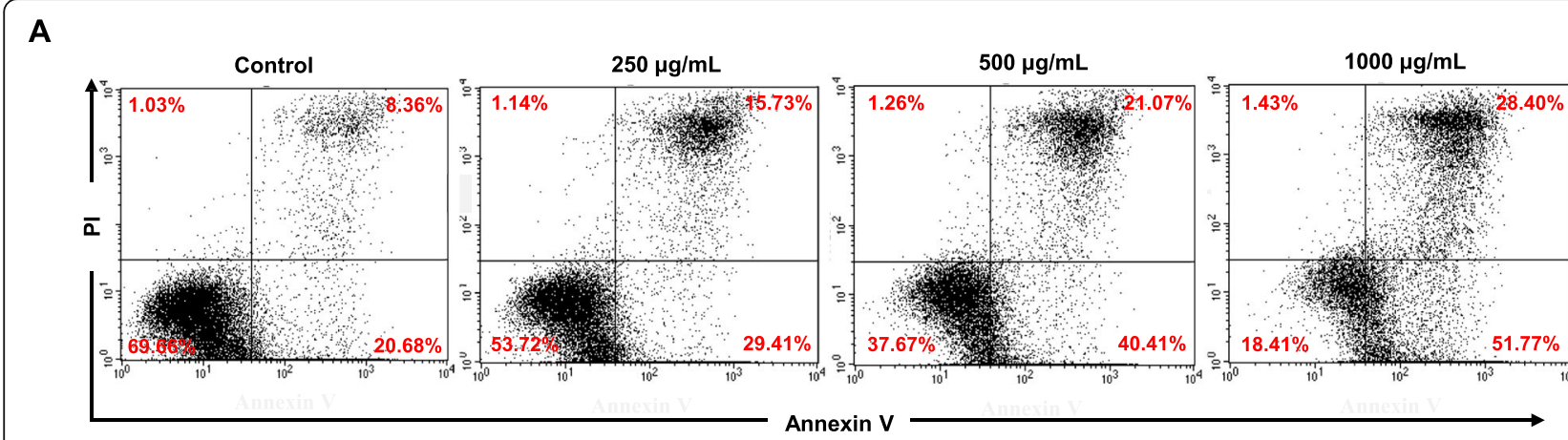

B

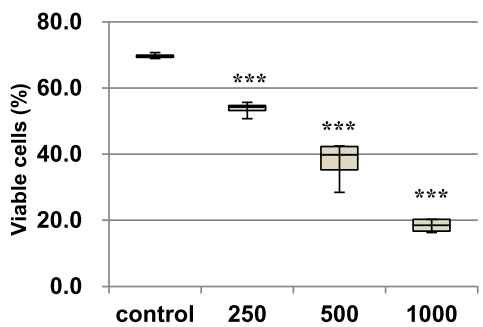

C

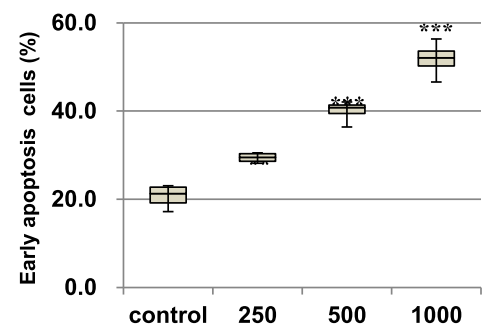

D

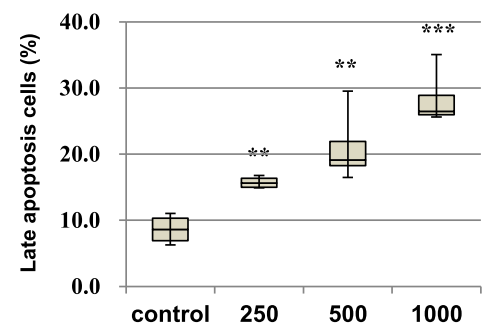

E

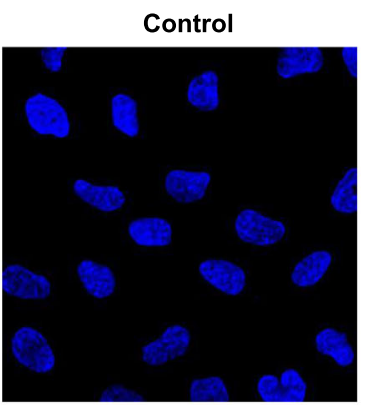

$500 \mu \mathrm{g} / \mathrm{mL}$

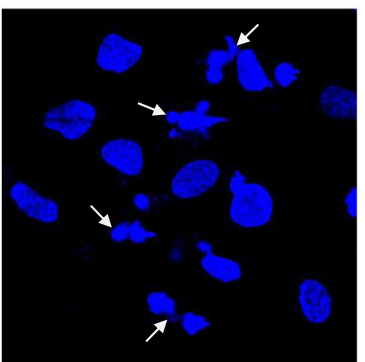

$250 \mu \mathrm{g} / \mathrm{mL}$

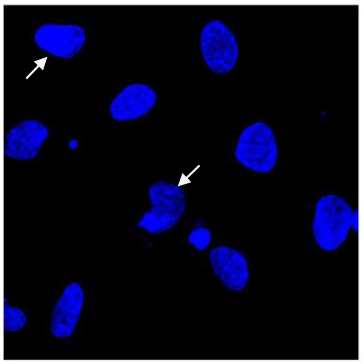

$1000 \mu \mathrm{g} / \mathrm{mL}$

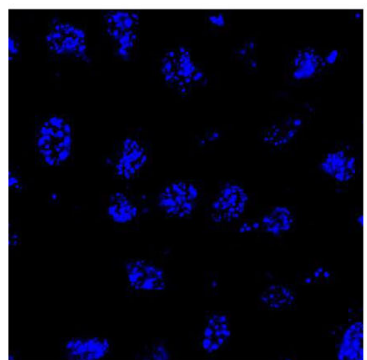

$\mathbf{F}$ $\begin{array}{lllll}0 & 250 & 500 & 1000 & \text { CLSE }(\mu g / m L)\end{array}$

p53
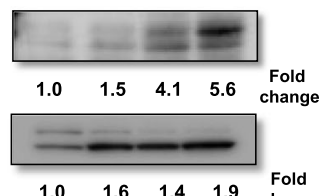

$\begin{array}{lllll}1.0 & 1.6 & 1.4 & 1.9 & \begin{array}{c}\text { Fold } \\ \text { change }\end{array}\end{array}$

Bax

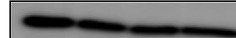

$\mathrm{Bcl}-2$

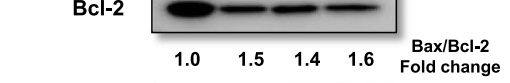

Cleaved cas -3

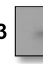

Cleaved cas-8

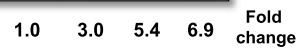

GAPDH

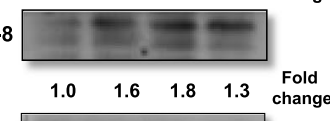

Fig. 4 Effects of Coix lacryma-jobi sprout extract (CLSE) on HeLa cell apoptosis. a-d HeLa cells were stained with FITC-annexin V/propidium iodide (PI) after treatment with various concentrations of CLSE $(0-1000 \mu \mathrm{g} / \mathrm{mL})$ for $72 \mathrm{~h}$, and cell populations and the extent of apoptosis were measured by flow-cytometric analysis. a Representative cell apoptosis dot plots for FITC-annexin V/PI staining in CLSE-treated cells. b-d Quantification of viable cells (FITC-annexin $\mathrm{V}^{-} / \mathrm{PI}^{-}$), early-apoptotic cells (FITC-annexin $\mathrm{V}^{+} / \mathrm{PI}^{-}$), and late-apoptotic cells (FITC-annexin $\mathrm{V}^{+} / \mathrm{PI}^{+}$) using four independent cell populations. e HeLa cells were stained with DAPI $(1 \mu \mathrm{g} / \mathrm{mL})$ after treatment with CLSE $(1-1000 \mu \mathrm{g} / \mathrm{mL})$ for $48 \mathrm{~h}$ and observed under a confocal microscope. Arrow, apoptotic cells (magnification: $\times 400)$. f HeLa cells were treated with CLSE $(1-1000 \mu \mathrm{g} / \mathrm{mL})$ for $72 \mathrm{~h}$, and apoptosisrelated proteins (p53, PARP, Bax, Bcl-2, cleaved caspase-3, and cleaved caspase-8) were examined using western blot analysis. ${ }^{* *} p<0.01$ and ${ }^{* * *} p<0.001$ versus control group. All data values are expressed as the mean \pm standard deviation $(n=4)$

Cell cycle progression is an important mechanism for homeostatic maintenance in normal cells [40]. However, the deregulation of cell cycle progression is a common characteristic of cancer cells [10]. Therefore, the regulation of the cell cycle in cancer cells is the basic question to be addressed prior to clinical studies for anticancer 


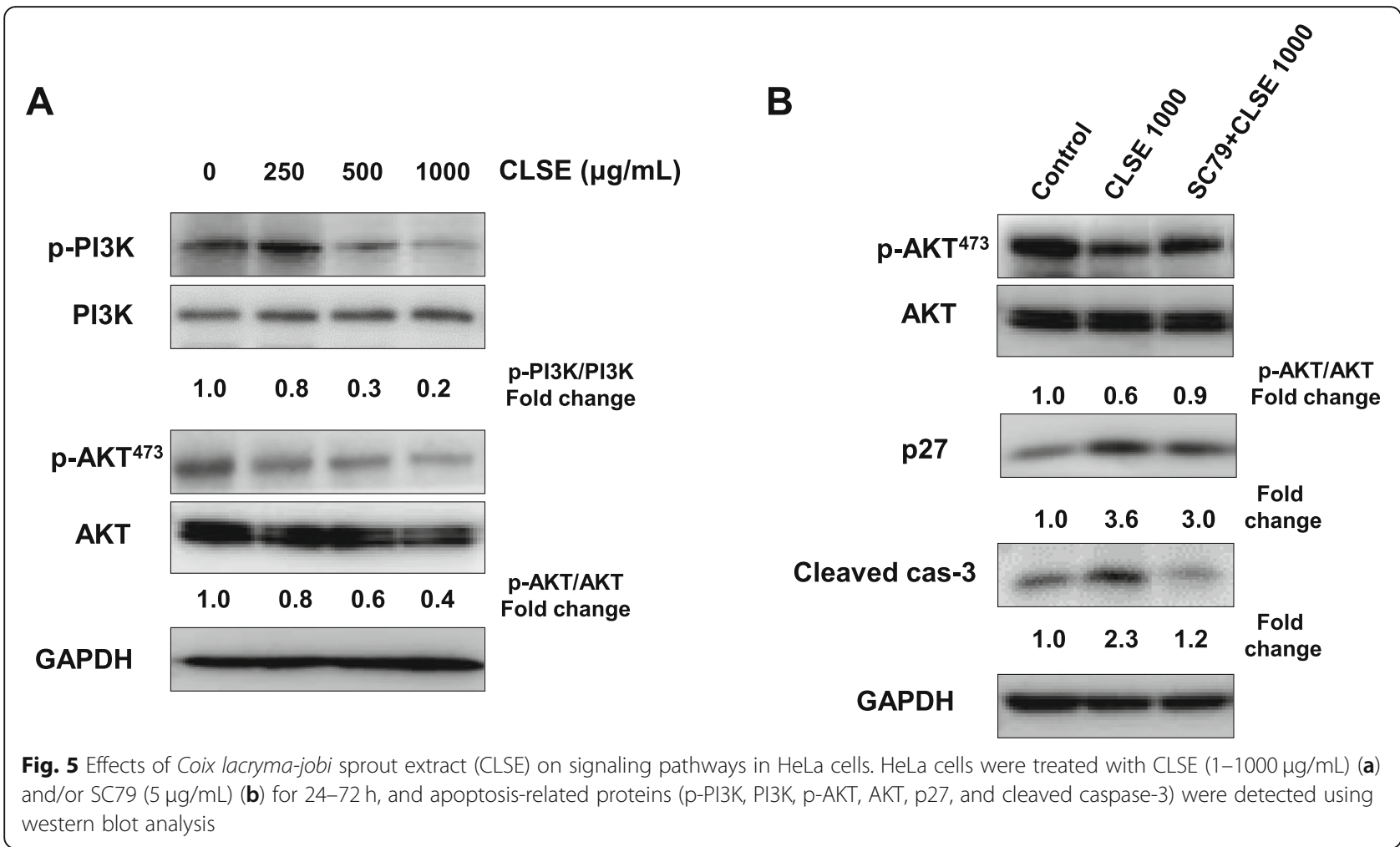

drug development [41]. In this study, CLSE inhibited HeLa cell proliferation, significantly decreased the percentage of $\mathrm{S}$ phase cells, and effectively increased the percentage of sub-G1 phase cells. However, CLSE did not promote the progression of the cell cycle to the G0/ G1 and G2/M phases. It has been reported that the antitumor activities of lung cancer cells mediated by a polysaccharide fraction of Coix seed were associated with S phase arrest and apoptosis. Although many studies have focused on G1 or G2 phases as DNA damage checkpoints, CLSE may specifically affect the proportion of $\mathrm{S}$ phase cells without regulating the G0/G1 or G2/M phases [42, 43].

Cell cycle regulation involves changes in the expression of three major classes of regulators: cyclins, CDKs, and cyclin-dependent kinase inhibitors (CDKIs) [11]. While the cyclin D/CDK4/CDK6 and cyclin E/CDK2 complexes modulate S-phase entry, these complexes are regulated by CDKIs [44]. CDKIs such as $\mathrm{p} 21^{\text {waf1/Cip1 }}$ and p27 ${ }^{\text {Kip1 }}$ are tumor suppressors that inhibit cell cycle progression by association with active cyclin/CDK complexes [7]. p21 ${ }^{\mathrm{CIP} 1}$ is required for cyclin $\mathrm{D} / \mathrm{CDK} 4$ assembly early in the G1 phase [45], whereas $\mathrm{p} 27^{\mathrm{KIP} 1}$ is a critical modulator of the G1/S transition. Furthermore, p21 ${ }^{\mathrm{CIP} 1}$ - / - mice do not develop spontaneous tumors, whereas $\mathrm{p} 27^{\mathrm{KIP} 1}-/$ - mice spontaneously develop both lung and pituitary adenomas [46]. Therefore, $\mathrm{p} 27^{\mathrm{KIP} 1}$ is a critical tumor suppressor that regulates the cell cycle.
On this basis, we showed that CLSE inhibited the protein levels of cyclin D and CDKs (CDK2, - 4, and - 6) and significantly increased p27 ${ }^{\mathrm{KIP} 1}$ expression level in HeLa cells. Collectively, our results suggest that CLSE regulates various molecules involved in $\mathrm{S}$ phase progression.

The three pathways leading to cell death are autophagy, apoptosis, and necrosis [47]. Most current anticancer drugs induce apoptosis of cancer cells. Apoptotic cell death has been suggested as an important mechanism for cancer chemotherapy and chemoprevention. Thus, agents that selectively induce apoptosis in cancer cells may be useful for cancer treatment. In this study, we found that CLSE induced the characteristic morphology of apoptosis, such as nuclear deformity, cell shrinkage, and nuclear fragmentation, in HeLa cells, and significantly induced dose-dependent increases in early- and late-apoptotic cells.

The regulation of Bax and $\mathrm{Bcl}-2$ in apoptotic cell death can be explained by their respective protein levels and the ratio of two proteins [48]. Generally, the $\mathrm{Bax} / \mathrm{Bcl}-2$ ratio is increased by high mitochondrial membrane permeability, which results in cytochrome $\mathrm{C}$ release from the mitochondria and the activation of downstream caspases [49]. Cleaved caspases are active forms and are considered robust signals of apoptosis [50]. Additionally, PARP and p53 are important factors for several important biological functions, such as DNA repair, cell cycle regulation, and apoptosis [16]. Thus, the upregulation of 
PARP cleavage and p53 by caspases is considered to be a hallmark of apoptosis [51]. Here, we found that the expression level of Bax did not change but the Bax/Bcl-2 ratio was increased in CLSE-treated HeLa cells. We also observed that CLSE induced the protein levels of p53, cleaved PARP, cleaved caspase- 3 , and cleaved caspase- 8 in HeLa cells. Although some CLSE concentration levels at $\mathrm{IC}_{50}$ appear too high to positively correlate the compound with the cancer cell cytotoxicity, results from other assays including FACS, DNA fragmentation, and western blot clearly demonstrate the anticancer effect of the CLSE.

PI3K/AKT signaling is involved in multiple cellular processes, such as survival and the proliferation of several cell types $[52,53]$. In addition, PI3K/AKT signal transduction is able to promote various cancers because this pathway modulates multiple cancer-related processes, such as proliferation, apoptosis, and metastasis, by regulating a number of downstream transcription factors [54, 55]. Many studies have reported that PI3K/ AKT signal transduction induces tumorigenesis, proliferation, inhibition of apoptosis, and chemoresistance [53]. In a previous study, we demonstrated that CLSE inhibited the migratory properties of colon cancer cells through repression of AKT and ERK1/2 phosphorylation in low-oxygen conditions. Our results also confirmed that CLSE downregulated the phosphorylation of PI3K and AKT; furthermore, AKT activation by SC79 decreased the expression of $\mathrm{p} 27$ and cleaved caspase- 3 proteins induced by CLSE in HeLa cells. Collectively, these data suggest that CLSE promotes cell cycle arrest and apoptosis through inhibition of AKT phosphorylation.

Although our research has reported anticancer effects of Coix sprout extract, more research on the stability and clinical effect of herbal medicines containing Coix is required. In the future, we will reinforce our findings by utilizing an in vivo mouse model and chemical analysis of active components of Coix sprout extract.

\section{Conclusion}

In this paper, CLSE showed antitumor activities in human cervical cancer cells. Specifically, CLSE treatment resulted in cell cycle arrest by reducing the proportion of $\mathrm{S}$ phase cells, decreasing the expression of cyclin $\mathrm{D}$ and CDKs (CDK2, - 4, and -6), elevating p2 $7^{\mathrm{KIP} 1}$ expression, and inducing apoptosis by upregulating p53, cleaved PARP, cleaved caspase- 3 , and cleaved caspase- 8 through impairment of the PI3K/AKT pathway. Consequently, CLSE may be an effective therapeutic agent for cervical cancer, as it may induce cell cycle arrest and apoptosis via inactivation of the PI3K/AKT pathways. In the future, we will further study the effectiveness of the antitumor activities of CLSE in cervical cancer.

\section{Abbreviations}

CCK-8: Cell Counting Kit-8; CDK: Cyclin-dependent kinase; CDKls: Cyclindependent kinase inhibitors; CLSE: Coix lacryma-jobi var. ma-yuen Stapf sprout extract; HPV: Human papillomavirus; PARP: Poly (ADP-ribose) polymerase; PBS: Phosphate-buffered saline; PS: Phosphatidylserine

\section{Acknowledgments}

Not applicable.

\section{Authors' contributions}

ESS and S-HK equally contributed to the research; YOK provided Coix Stapf sprout extract for this research; YEL, SYK and SHJ analyzed the data; both YJK and J-WP wrote the manuscript with input from all authors and supervised the findings of this work. All authors discussed the results and contributed to the final manuscript. All authors read and approved the final manuscript.

\section{Funding}

This work was supported by Gachon University Gil Medical Center (FRD201710-02) (to J.-W.P. and S.-H.K.), the Korea Research Foundation (2018R1D1A1B07048747) (to S.-H.K.), and the Rural Development Administration (PJ0127852017) (to Y.O.K.). The funding bodies provided financial support.

\section{Availability of data and materials}

The data that support the findings of this study are available from the corresponding author upon reasonable request.

Ethics approval and consent to participate Not applicable.

\section{Consent for publication}

Not applicable.

\section{Competing interests}

The authors declare that they have no competing interests.

\section{Author details}

${ }^{1}$ Department of Allergy, Pulmonary and Critical Care Medicine, Gachon University, Gil Medical Center, Incheon 21565, Republic of Korea. ${ }^{2}$ Gachon Medical Research Institute, Gachon University Gil Medical Center, Incheon 21565, Republic of Korea. ${ }^{3}$ Department of Bio-Environmental Chemistry, College of Agriculture and Life Sciences, Chungnam National University, Daejeon 34134, Republic of Korea. ${ }^{4}$ Division of Pulmonology, Department of Internal Medicine, Korea University Ansan Hospital, Gyeonggi-do 15355, Republic of Korea.

Received: 25 August 2019 Accepted: 23 October 2019

Published online: 15 November 2019

References

1. Bray F, Jemal A, Grey N, Ferlay J, Forman D. Global cancer transitions according to the human development index (2008-2030): a populationbased study. Lancet Oncol. 2012;13(8):790-801.

2. McGuire S. World cancer report 2014. Geneva, Switzerland: World Health Organization, International Agency for Research on Cancer, WHO press, 2015. Adv Nutr. 2016;7(2):418-9.

3. Villa LL. Human papillomaviruses and cervical cancer. Adv Cancer Res. 1997; 71:321-41.

4. Kim MK, Kim HS, Kim SH, Oh JM, Han JY, Lim JM, et al. Human papillomavirus type 16 E5 oncoprotein as a new target for cervical cancer treatment. Biochem Pharmacol. 2010;80(12):1930-5.

5. Moody CA, Laimins LA. Human papillomavirus oncoproteins: pathways to transformation. Nat Rev Cancer. 2010;10(8):550-60.

6. Surviladze Z, Sterk RT, DeHaro SA, Ozbun MA. Cellular entry of human papillomavirus type 16 involves activation of the phosphatidylinositol 3kinase/Akt/mTOR pathway and inhibition of autophagy. J Virol. 2013;87(5): 2508-17.

7. Fulda S, Meyer E, Friesen C, Susin SA, Kroemer G, Debatin KM. Cell type specific involvement of death receptor and mitochondrial pathways in drug-induced apoptosis. Oncogene. 2001;20(9):1063-75. 
8. Jemal A, Center MM, DeSantis C, Ward EM. Global patterns of cancer incidence and mortality rates and trends. Cancer Epidemiol Biomark Prev. 2010;19(8):1893-907.

9. Sherwood SW, Sheridan JP, Schimke RT. Induction of apoptosis by the antitubulin drug colcemid: relationship of mitotic checkpoint control to the induction of apoptosis in HeLa S3 cells. Exp Cell Res. 1994;215(2):373-9.

10. Evan Gl, Vousden $\mathrm{KH}$. Proliferation, cell cycle and apoptosis in cancer. Nature. 2001:411(6835):342-8.

11. Grana X, Reddy EP. Cell cycle control in mammalian cells: role of cyclins, cyclin dependent kinases (CDKs), growth suppressor genes and cyclindependent kinase inhibitors (CKIs). Oncogene. 1995;11(2):211-9.

12. Hall M, Peters G. Genetic alterations of cyclins, cyclin-dependent kinases, and Cdk inhibitors in human cancer. Adv Cancer Res. 1996:68:67-108.

13. Dulic V, Kaufmann WK, Wilson SJ, TIsty TD, Lees E, Harper JW, et al. p53dependent inhibition of cyclin-dependent kinase activities in human fibroblasts during radiation-induced G1 arrest. Cell. 1994;76(6):1013-23.

14. Murray A. Cell cycle checkpoints. Curr Opin Cell Biol. 1994;6(6):872-6.

15. Thompson CB. Apoptosis in the pathogenesis and treatment of disease. Science. 1995;267(5203):1456-62.

16. Li-Weber M. Targeting apoptosis pathways in cancer by Chinese medicine. Cancer Lett. 2013:332(2):304-12.

17. Efferth T, Li PC, Konkimalla VS, Kaina B. From traditional Chinese medicine to rational cancer therapy. Trends Mol Med. 2007;13(8):353-61.

18. Dong FY, Jiang RW. Research progress of the natural products against prostate cancer. Chin J Nat Med. 2011;9(2):81-9.

19. Liu M, Ohtani H, Zhou W, Orskov AD, Charlet J, Zhang YW, et al. Vitamin C increases viral mimicry induced by 5-aza-2'-deoxycytidine. Proc Natl Acad Sci U S A. 2016:113(37):10238-44.

20. Siegel RL, Miller KD, Jemal A. Cancer statistics. CA Cancer J Clin. 2016;66(1):7-30.

21. Singh S, Sharma B, Kanwar SS, Kumar A. Lead phytochemicals for anticancer drug development. Front Plant Sci. 2016;7:1667.

22. Huang SCY, Chiang W. Amino acids, fatty acids and proximate composition of the seed of adlay. Food Sci. 1994;21:67-74.

23. Woo JH, Li D, Wilsbach K, Orita H, Coulter J, Tully E, et al. Coix seed extract, a commonly used treatment for cancer in China, inhibits NFkappaB and protein kinase C signaling. Cancer Biol Ther. 2007;6(12):2005-11.

24. Chang HC, Huang YC, Hung WC. Antiproliferative and chemopreventive effects of adlay seed on lung cancer in vitro and in vivo. J Agric Food Chem. 2003:51(12):3656-60.

25. Kuo CC, Shih MC, Kuo YH, Chiang W. Antagonism of free-radical-induced damage of adlay seed and its antiproliferative effect in human histolytic lymphoma U937 monocytic cells. J Agric Food Chem. 2001;49(3):1564-70.

26. Lee MY, Lin HY, Cheng F, Chiang W, Kuo YH. Isolation and characterization of new lactam compounds that inhibit lung and colon cancer cells from adlay (Coix lachryma-jobi L. var. ma-yuen Stapf) bran. Food Chem Toxicol. 2008:46(6):1933-9.

27. Lu Y, Wu LQ, Dong Q, Li CS. Experimental study on the effect of Kang-LaiTe induced apoptosis of human hepatoma carcinoma cell HepG2. Hepatobiliary Pancreat Dis Int. 2009;8(3):267-72.

28. Manosroi A, Sainakham M, Chankhampan C, Manosroi W, Manosroi J. In vitro anti-cancer activities of Job's tears (Coix lachryma-jobi Linn.) extracts on human colon adenocarcinoma. Saudi J Biol Sci. 2016;23(2):248-56.

29. Sangronis $E$, Machado CJ. Influence of germination on the nutritional quality of Phaseolus vulgaris and Cajanus cajan. Lwt-Food Sci Technol. 2007; 40(1):116-20.

30. Son ES, Kim YO, Park CG, Park KH, Jeong SH, Park JW, et al. Coix lacryma-job var. ma-yuen Stapf sprout extract has anti-metastatic activity in colon cancer cells in vitro. BMC Complement Altern Med. 2017;17(1):486.

31. Zigras T, Lennox G, Willows K, Covens A. Early cervical cancer: current dilemmas of staging and surgery. Curr Oncol Rep. 2017;19(8):51.

32. Hassan AHE, Choi E, Yoon YM, Lee KW, Yoo SY, Cho MC, et al. Natural products hybrids: 3,5,4'-Trimethoxystilbene-5,6,7-trimethoxyflavone chimeric analogs as potential cytotoxic agents against diverse human cancer cells. Eur J Med Chem. 2019;161:559-80.

33. Wang Y, Li Y, Liu X, Cho WC. Genetic and epigenetic studies for determining molecular targets of natural product anticancer agents. Curr Cancer Drug Targets. 2013;13(5):506-18.

34. Desai AG, Qazi GN, Ganju RK, El-Tamer M, Singh J, Saxena AK, et al. Medicinal plants and cancer chemoprevention. Curr Drug Metab. 2008;9(7):581-91.
35. Zhang PR, Meng XY, Tang XH, Ren L, Liang J. The effect of a coix seed oil injection on cancer pain relief. Support Care Cancer. 2019;27(2):461-5.

36. Wang D, Yang CD, Wang ZE, Yang Y, Li DF, Ding XJ, et al. Norcantharidin combined with Coix seed oil synergistically induces apoptosis and inhibits hepatocellular carcinoma growth by downregulating regulatory $T$ cells accumulation. Sci Rep. 2017;7(1):9373.

37. Lu X, Liu W, Wu J, Li M, Wang J, Wu J, et al. A polysaccharide fraction of adlay seed (Coixlachryma-jobi L.) induces apoptosis in human non-small cell lung cancer A549 cells. Biochem Biophys Res Commun. 2013;430(2):846-51.

38. Bao Y, Yuan Y, Xia L, Jiang H, Wu W, Zhang X. Neutral lipid isolated from endosperm of Job's tears inhibits the growth of pancreatic cancer cells via apoptosis, G2/M arrest, and regulation of gene expression. J Gastroenterol Hepatol. 2005;20(7):1046-53.

39. Moreno DA, Perez-Balibrea S, Garcia-Viguera C. Phytochemical quality and bioactivity of edible sprouts. Nat Prod Commun. 2006;1(11):1037-48.

40. Zhang J, Wang L, Zhang Y. Downregulation of NIMA-related kinase-7 inhibits cell proliferation by inducing cell cycle arrest in human retinoblastoma cells. Exp Ther Med. 2018;15(2):1360-6.

41. Sherr CJB, J. Cell cycle-targeted cancer therapies. Annu Rev Cancer Biol. 2017;1(1):41-57.

42. Shi Z, Azuma A, Sampath D, Li YX, Huang P, Plunkett W. S-phase arrest by nucleoside analogues and abrogation of survival without cell cycle progression by 7-hydroxystaurosporine. Cancer Res. 2001;61(3):1065-72.

43. Toogood PL. Progress toward the development of agents to modulate the cell cycle. Curr Opin Chem Biol. 2002;6(4):472-8.

44. Morgan DO. Principles of CDK regulation. Nature. 1995:374(6518):131-4.

45. Banwell CM, Singh R, Stewart PM, Uskokovic MR, Campbell MJ. Antiproliferative signalling by $1,25(\mathrm{OH}) 2 \mathrm{D} 3$ in prostate and breast cancer is suppressed by a mechanism involving histone deacetylation. Recent Results Cancer Res. 2003;164:83-98.

46. Ivanchuk SMR, J. T. Regulation of the cell cycle and interventional developmental therapeutics. In: Handbook of brain tumor chemotherapy; 2006. p. 123-40.

47. Zhang Y, Wu J, Xu W, Gao J, Cao H, Yang M, et al. Cytotoxic effects of Avermectin on human HepG2 cells in vitro bioassays. Environ Pollut. 2017; 220(Pt B):1127-37.

48. Cory S, Adams JM. Killing cancer cells by flipping the Bcl-2/Bax switch. Cancer Cell. 2005;8(1):5-6.

49. Peng Y, Guo C, Yang Y, Li F, Zhang Y, Jiang B, et al. Baicalein induces apoptosis of human cervical cancer HeLa cells in vitro. Mol Med Rep. 2015; 11(3):2129-34

50. Fan TJ, Han LH, Cong RS, Liang J. Caspase family proteases and apoptosis. Acta Biochim Biophys Sin Shanghai. 2005;37(11):719-27.

51. Shin HJ, Kwon HK, Lee JH, Gui X, Achek A, Kim JH, et al. Doxorubicininduced necrosis is mediated by poly-(ADP-ribose) polymerase 1 (PARP1) but is independent of p53. Sci Rep. 2015;5:15798.

52. Sun $H$, Wang Z, Yakisich JS. Natural products targeting autophagy via the $\mathrm{PI3K} / \mathrm{Akt} / \mathrm{mTOR}$ pathway as anticancer agents. Anti Cancer Agents Med Chem. 2013;13(7):1048-56

53. Matsuda S, Ichimura M, Ogino M, Nakano N, Minami A, Murai T, et al. Effective PI3K modulators for improved therapy against malignant tumors and for neuroprotection of brain damage after tumor therapy (review). Int J Oncol. 2016:49(5):1785-90.

54. Toren P, Zoubeidi A. Targeting the PI3K/Akt pathway in prostate cancer: challenges and opportunities (review). Int J Oncol. 2014;45(5):1793-801.

55. Yu HG, Ai YW, Yu LL, Zhou XD, Liu J, Li JH, et al. Phosphoinositide 3-kinase/ Akt pathway plays an important role in chemoresistance of gastric cancer cells against etoposide and doxorubicin induced cell death. Int J Cancer. 2008;122(2):433-43.

\section{Publisher's Note}

Springer Nature remains neutral with regard to jurisdictional claims in published maps and institutional affiliations. 